\title{
From Enlightenment to Equality: Spirituality May Lead the Way to a Gender Just Society in India and Beyond ERIN SMITH
}

\begin{abstract}
India is a country of spiritual traditions and paradoxes. Its spiritual verve offers sustenance through personal transformation, truth, harmony, and connection, yet today large numbers of people in India struggle against poverty, abuses, injustice, and inequalities. India is a land of daughters, known for their valour, hope, knowledge, and wealth of spirit, yet today the status of women is one of the country's greatest challenges and gender equality is fighting an often-silent battle. This study was conceived from the notion that Indian spirituality, in its truest essence, is the antithesis to this gender paradigm, and accordingly, it examined if spirituality can work to achieve a more gender equal and just society. Organized with the support of Dev Sanskriti University, this pilot study sought to uncover a correlation between participants' spirituality and their beliefs about gender roles, their gender equal attitudes, and gender equal behavior in the home. Though findings revealed no exceptional correlation, results identified a relationship between spirituality and gender equality within which gender discourse should focus and further research should follow. Gender inequality is pervasive in all countries, and such a global crisis deems further exploration into spirituality and gender equality not only compelling but also necessary.
\end{abstract}

Key words : Spirituality, Gender Equality, Gender Roles, Patriarchy and Sustainable Development

"May Almighty illuminate our consciousness and inspire us towards the righteous path."

-Gayatri Mantra

The culture of India is one like no otherstrengthened in its occupation with spirituality and the Vedas. Yet, the harsh realities of society and of women and girls in particular make clear the exploitative and patriarchal thinking that has undermined Vedic qualities of consciousness, connection, and compassion. Despite 50 years of progress in human rights, the country's struggle with gender inequality remains a startling and palpable challenge to development, especially for those aspiring to ethical and sustainable development (Mugali, 2014). India currently ranks an embarrassing 136 out of 186 countries in the UN's Gender Inequality Index, and the UN Development Program recognizes women as one of India's most marginalized groups and pressing challenges (UNDP, 2014). The above translation of the Gayatri Mantra wonderfully captures the essence of Indian Spirituality and defines what is, at its core, needed for society to elevate women to an equal and just status. In a way, this study sought to answer if, through spirituality and spiritual practices, the Almighty is able to step up to the challenge.

\section{Gender Inequality and India's Uncertain Road to Sustainable Development}

Gender equality's role in India's sustainable development falls within a systems approach, thought as the only viable way to work within the development field; it considers that all aspects, including institutions, ideas, and beliefs, will directly or indirectly affect outcomes (Kothari, 2013). An open economy, climate change, and a globalized world have in undated Indian lives with instability and forceful adaptation (Pande, 2007; Shiva, \& Bedi, 2002). Sustainable development addresses the myriad of social, political, cultural, and environmental conflicts, challenges, and 
opportunities that arise with such change. The UN highlights gender equality for successful development planning and outcomes (UN Women, 2014). Male hegemony [or domination in any form], sparks corruption and curtails development practices designed to liberate women, men, and communities (Rowen-Campbell, 1999, p.11). By definition, social justice, the feminist movement, and a gender perspective become central attributes to a sustainable development paradigm. This study stems from the current body of knowledge on gender and development while filling a gap that development researchers admit exists in the realm of spirituality (Ver Beek, 2000).

\section{Understanding Inequality}

The UN defines gender as the socially constructed attributes and opportunities ascribed to individuals based on their sex rather than biologically determined characteristics (UN Women, 2014). In this study, gender equality is defined as equal physical, emotional, and mental liberty and wellbeing between genders and the absence of barriers to equitable opportunity and agency based on gender identity. Under this definition, gender equality is a fundamental human right across cultures and contexts. Despite strides in India, gender injustice--from the violent and shocking to the subtle and often overlooked--still manifest in all sectors; analysis of Indian economy, education, health, and law gives a slight glimpse into the challenges $^{1}$.

Women's status in these sectors and inequality in the family structure represent an entire complex patriarchal system (Sharpe, 2003, p.283). The system relies on strict and biased gender roles and identities based on Essentialism, a theory that claims there are "inherent or natural features" that characterize men and women [outside of physical attributes]" (Kabir \& Kumar, 2003). Together they justify a division of labor and lifestyle that exploits and regulates women in their "roles, responsibilities, mobility, sexuality, and independence" by male counter parts and institutions (VanKlinken, 2013, p. 276). This study gauged participants' belief in essentialism, which contradicts the theory of social constructivism that most modern scholars conclude is superior (Derné 1994; Alsop et al., 2002, p.130; VanKlinken, 2013). Like the UN's defi,nition of gender, Social constructivism states that categories of man and woman are "attached to social and symbolic meanings" rooted in "cultural and religious ideologies" [and thus controlled by popular belief rather than science] (VanKlinken, 2013, p. 276).

\section{India's Prevailing Patriarchy}

Patriarchy and gender inequality were ingrained and exacerbated through unique elements in Indian history ${ }^{2}$. Their origins are traced to around 1500 B.C. and the brahmanical social order that divested women's religious and scriptural authority (Chakravarti, 1993, p.579). This era also saw society stratified by hierarchal caste distinctions that deemed women's independence a threat to protected societal and familial structures. The caste system became a useful tool to justify and perpetuate strict gender roles through an array of violations- child brides and forced marriage, practical imprisonment of the daughter in the home, subordination of the daughter-in-law, dowry, sati, and the stripping of female agency (Chakravarti, 1993, p.579). Although this history is quite literally ancient, patriarchy in India prevails, still dominating today through many of the same practices. ${ }^{3}$

Historical understanding of patriarchy in India and modern-day observation explain the manifestation of gender inequality in the family and the directing of this study's focus to life in the home. Gender inequality, female subjugation, and the inherent dilemma for all Indian people demand reparation of the crisis. Extensive research has examined empowerment and its effectiveness 
through economic development, education, and gender focused legal policies; most work concludes that severe challenges still exist ${ }^{4}$.

\section{A Missing Piece}

Indian philosopher Kreet Joshi explained, "the unique greatness and continuity of Indian culture can be traced to her unparalleled experimentation, discovery and achievement in the vast field of spirituality" (Joshi, 1992, p.56). Studies reveal that religion and spirituality strongly affect an individual's development, identity, belief system, and cultural paradigm ${ }^{5}$. One can assume that likened attitudes, behaviors, and institutions, including those regarding gender, culminate as a result. Despite these truths, spirituality in India remains a virtually untapped resource in gender equality programs and research.

It is important to note the difference between spirituality and religion however. Though the two can coexist in one's life, religion is extrinsic and reflects constructed behaviors of group membership, coherent theology, belief systems, and worship (Bryant, 2007, p.835). Spirituality is intrinsic and instead defines an individual process, experience, and state of being in search of connection with something transcending human existence (Passalacqua \& Cervantes, 2008, p.224). Research shows that spirituality has a more profound and positive impact on a person's psyche and actions than religiousness or religion alone (Fukuyama \& Sevig, 1999; Berkel et al., 2004; Bryant, 2007).

\section{The Spiritually Awakened Reality and Gender Theory}

Both religion and spirituality exist in India today, but the true nature of spirituality is separate of religion and rooted in metaphysics and the Vedas (Joshi, 1999). Though Vedic spiritual concepts are experiential phenomenon and thus difficult to define, these aspirations underline the study's scope, and understanding their nature forms a hypothesis wherein spirituality and gender equality are related. Knapp (2006) describes that spirituality in India, or Sanatana-Dharma, is a path to understanding oneself, one's divinity, and one's inherent nature, which is ultimately "love for all things" The ego and physical forms belong to the world of senses and illusion (Knapp, 2006). Acharya (2014) said that when one experiences Atman (the soul) as the true reality, negative thoughts, character, and behavior stemming from the illusion are purified (p.19). Theoretically speaking, spiritual practice can lead to the pure consciousness, compassion, forgetting of ego, and refinement in character needed for destroying patriarchal structures. In addition, an elevated state of mind reveals the physical body as an illusion and the concept of gender roles can be naturally alleviated.

Spiritual teachers then relay that a profound understanding of the collectiveness of all life can be accessed from this state. Acharya (2014) explains that when ascending towards enlightenment, the sense of belonging expands until "one discovers that [s]he is one with all existence" and the "body-confined sense of I-ness vanishes for good" (p.21). One awakens to the self as one spark in the transcending Vishuddha Atma, or "pure, ultimate, Immutable Super Soul" of which all else is and belongs (Acharya, 2014, p.20, 65). Joshi (1999) describes spirituality as "a realm of truths, powers and ecstasies" that we can experience and express directly (p.56). Vedic insight into these truths magnifies a spiritual fabric of life where practices, experiences, and realizations of oneness ought to lead to critical awareness of inequalities and exploitative gender paradigms. For achieving equality, selfexploration essentially leads to a place of connection and consciousness where all distinction between lives, and therefore genders, should by logic fall away. 


\section{Testing the Spiritual Theory}

Pure knowledge and absolute connection lie at the heart of spirituality in India, and thus premise for biases, stereotyping, and different treatment based on biological sex should theoretically have no place. To examine this theory, this study sought to uncover if correlations existed between participants' spirituality and their beliefs about gender equality and gender roles and identities. It next assessed if spirituality correlated with participants' gender equal behaviors in the home, comparing husbands to wives and sons to daughters, and evaluating equal workloads, agency, autonomy, and access to public space, finances, and opportunities. Finally, the study discovered if participants practicing healthy gender behaviors in the family believed that spirituality helped them to better understand gender equality. It then assessed if those individuals differed from their parental examples, which could confirm a departure from the process of socialization that may be due to spiritual formation.

\section{METHOD}

This is an exploratory study with the staff members of Dev Sanskriti Vishwavidyalaya in Haridwar, Uttarakhand. It is a qualitative study to uncover in-depth understanding of human beliefs and behavior, primarily using an extensive written survey questionnaire.

Exploratory data analysis summarized and identified patterns in findings. Results for survey sections 1 and 2 used a numerical valuation (from $0-4)$ of each response to total and categorize within labeled parameters the results for participants' level of spirituality and beliefs about gender equality and gender roles. These labeled parameters were then used to make correlations between concepts (See table-1). Section (3) evaluated gender equal behaviors in the home, where any major life choice made "usually" by one spouse defined an inequality in agency. Inequality between son and daughter was defined as any discrepancy in treatment or expectations. One spouse habitually working at least $35 \%$ more hours a week compared to the other (outside job and housework combined) characterized an unequal workload. To define a final correlation between aspects of spirituality and aspects of gender equality, the study required results show $60 \%$ or more subjects (or at least 15 of 25) presenting the correlation, else a correlative conclusion was not made.

The study's scope was limited to individuals who believed spirituality to be important in their lives. Opportunity sampling was necessitated based on the timeline of the study and comprised a heterogeneous group of men and women, married and unmarried, from a range of different ages and educational, caste, socioeconomic, and urban/rural backgrounds. Two hundred surveys were dispersed; 25 were completed and retrieved. Participants included 16 married males, one unmarried male, 7 married females, and one unmarried female, possessing a Bachelor's degree or higher, ranging from 28 to 66 years in age. This study adhered to all ethical and sensitivity guidelines of the local review board and all participants' personal identification remained anonymous. 


\section{FINDINGS}

Table (1) explains the relationships between variables used to define a correlation:

\begin{tabular}{|l|l|l|l|l|}
\hline $\begin{array}{l}\text { Definition of } \\
\text { Correlations } \\
\text { Between }\end{array}$ & Spiritual Measurement & $\begin{array}{l}\text { Beliefs about Gender } \\
\text { Roles }\end{array}$ & $\begin{array}{l}\text { Beliefs about } \\
\text { Gender } \\
\text { Equality }\end{array}$ & $\begin{array}{l}\text { Gender Equality in } \\
\text { the Home }\end{array}$ \\
\cline { 2 - 5 } & Very Strong to Strong & Non-Strict & Good & Good \\
\cline { 2 - 5 } & Weak & Somewhat Strict & Fair & Fair \\
\cline { 2 - 5 } & Very Weak to None & Strict to Very Strict & Poor & Poor to Non-existent \\
\hline
\end{tabular}

Using these parameters, less than $60 \%$ of the respondents showed a correlation between spirituality and beliefs about gender equality, beliefs about gender roles, or gender equal behavior in the home. Respondents who showed gender equal behavior in the home did not, in general, differ from their parental example.

Connection, disillusionment and discovering a disconnect (Outcomes 1 and 2)

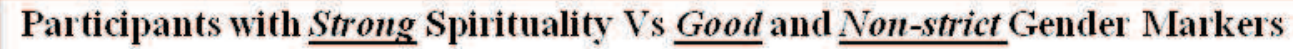

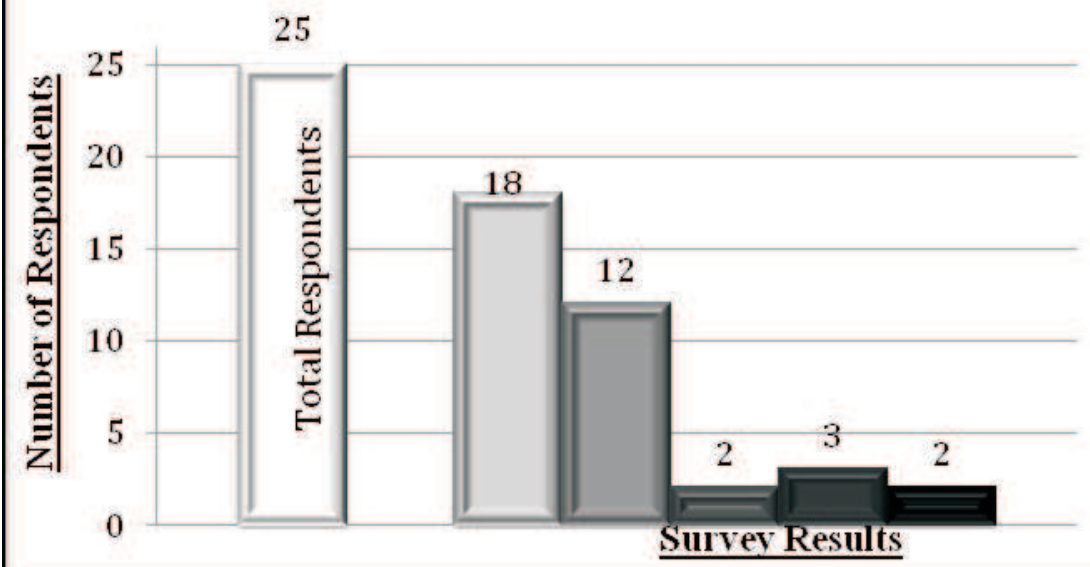

Disillusionment of the Physical World through Spirituality

Connection through Spirituality

--Beliefs about Gender Equality

---Beliefs about Gender Roles

Gender Equal Behavior in the Home

*The number of respondents showing strong aspects of spirituality was relatively high, while the numbers showing good beliefs about gender equality, non-strict beliefs about gender roles, and good gender equal behavior in the home were significantly lower, showing a disconnect.

Table (2) displays total participant correlations between aspects of spirituality and gender measures

\begin{tabular}{|l|l|l|}
\hline \multirow{2}{*}{} & \multicolumn{2}{|l|}{ Participants who demonstrated correlation in: } \\
\cline { 2 - 3 } & Sense of Connection & $\begin{array}{l}\text { Sense of Disillusionment of the } \\
\text { Physical World }\end{array}$ \\
\hline Beliefs about Gender Roles & 11 out of $25(44 \%)$ & 6 out of $25(24 \%)$ \\
\hline Beliefs about Gender Equality & 13 out of $25(52 \%)$ & 7 out of $25(28 \%)$ \\
\hline Gender Equal Behavior in the Home & 9 out of $25(36 \%)$ & 6 out of $25(24 \%)$ \\
\hline
\end{tabular}


*Less than $60 \%$ of participants showed a correlation between each spiritual measure and gender measure, so this study did not define any conclusive correlations between aspects. Note-more participants showed a correlation between gender measures and connection than gender measures and disillusionment of the physical world.

** In addition, those who scored highest (top five) for sense of connection through spirituality also scored highest for all gender markers. Similarly, those who scored lowest (bottom five) for sense of connection also scored lowest for all gender markers. These findings show a relationship exists between sense of connection and the gender markers, though not a sharp correlation as defined by the study.

\section{Socialization wins over Spirituality (Outcome 3)}

All 25 respondents strongly agreed that spirituality improved their understanding of gender equality, but only two participants showed good gender equal behavior in the home. Both participants had a good parental example for gender equal behavior, so a departure from socialized gender behavior due to spiritual formation could not be confirmed.

\section{Beliefs that are striking -Gender Equality and Gender Roles}

Table (3) displays notable results for Beliefs about Gender Equality

\begin{tabular}{|l|c|c|}
\hline Survey Question: & Strongly Agreed & Agreed \\
\hline Gender equality is good for India & $84 \%$ & $8 \%$ \\
\hline Gender inequality is still a problem in India today & $36 \%$ & $28 \%$ \\
\hline Women should have the same rights as men & $48 \%$ & $40 \%$ \\
\hline It is good for a woman to share her opinion & $8 \%$ & $8 \%$ \\
\hline
\end{tabular}

*Examples are seen showing a discrepancy in beliefs. Although the majority strongly agreed that gender equality is good for India, less than half strongly agreed it is a problem today or that women and men should have the same rights.

Table (4) displays notable results for Beliefs about Gender Roles

\begin{tabular}{|l|c|}
\hline Survey Question: & Agreed or Strongly Agreed \\
\hline Men should be emotionally stronger than women & $68 \%$ \\
\hline Men should make the most income and thus hold the power in the family & $68 \%$ \\
\hline It is the duty of a daughter-in-law to obey her in-laws & $80 \%$ \\
\hline Women should be most responsible for taking care of the home and cooking & $84 \%$ \\
\hline $\begin{array}{l}\text { It is the mother's responsibility to change diapers, give baths, and feed the } \\
\text { children }\end{array}$ & $84 \%$ \\
\hline
\end{tabular}

*Examples are seen of a striking majority showing Very Strict/Strict Beliefs about Gender Roles. *Twenty-three of 25 participants (92\%) showed unequal workloads in the family, with the female habitually working at least $35 \%$ more hours a week than her husband. 


\section{DISCUSSION}

Though correlations between spiritual beliefs and gender beliefs and behaviors could not be concluded, the sense of connection through spirituality had interesting results. Since the top and bottom scores for gender equal beliefs and behavior in the home were in-line with the top and bottom scores for connection through spirituality, it may suggests that in its strong presence or strong absence, sense of connection affects gender equal concepts. Had the guidelines for correlation not been so rigid, or quantitative methods of deduction been used, (e.g., the correlation coefficient), correlations would have been more easily noted for spiritual connection.

Gender equal behavior in the home of the participants is also interesting. Only two people were found to have "Good" gender behaviors, twelve participants would have qualified had equal workload not been a factor. This may indicate that connection through spirituality can influence gender equal behaviors in decision-making, financial equality, and treatment of sons and daughters, but that a disconnect lies deeper in realizing a fair and equal division of labor. The study revealed that beliefs about gender roles could be the force behind the behavior. Those with the presence of physical violence in the home, the most overt form of inequality, showed to have the strictest sense of gender roles. Of the participants in this study, the housewife position was related to violence, strict gender roles, and inequality, however it should not be assumed that, outside of this group, a woman working in the home predicts inequality in the marriage.

"'Man' and 'woman' are at once empty and overflowing categories. Empty because they have no ultimate, transcendent meaning. Overflowing because, even when they appear to be fixed, they still contain within them alternative, denied or suppressed definitions"'(Scott,1988, p.61)
The above quote is significant to this study. The participants, to varying degrees, seem to have not yet realized its truth to the fullest extent. Most respondents at least agreed that men and women are equal, failing to realize the implications of strict gender roles or their maintenance of a patriarchal system. A major finding was that women were significantly overworked compared to their husbands (as a result of men generally taking far less responsibility for duties of the home and/or children). Research shows that women face physical, mental, and emotional burdens as a result of this standard (Hooks, 2000, P.79). Furthermore, male participants are also victims to these gender roles, evidenced by the majority response that stated men "should be emotionally stronger than women" and that fathers should be the secondary caretakers of children.

The social constructivist perspective explains that men are socialized into masculinities that maintain gender inequalities, such as being "critically judged" based on achievement, success, power, emotional restriction, and aggressiveness-a value set this study assessed and found present in its subjects (Alsop \& Lennon, 2002, p.130). The mentality not only creates a culture of domination, but men are taught "to suppress a range of emotions, needs, and possibilities such as nurturing, receptivity, empathy, and compassion, which are experienced as inconsistent with the power of manhood" (Kaufman, 1999). Women are socialized into an "ideal feminine role" that stresses "conflict resolution, submission, gentleness, [and] nurturance" (Bryant, 2007, p.838) and emphasizes "modesty, obedience, selfsacrifice and attachment to the home" (Derné, 1994, p.205). Again, this portrays a value system revealed via the participants' responses. Sadly, these blindly prescribed attributes successfully limit women's freedom, agency, and mobility, 
subordinating their positions to male family members and reinforcing gender injustice in India (Derné, 1994, p.205). Men and women in this study equally upheld these patriarchal norms, thereby confirming an idea that both males and females perpetuate inequality.

\section{Conclusion}

This study examined if spirituality in India can help achieve a more gender equal and just society and uncovered whether correlations exist between the presence of spirituality and spiritual practices, and the presence of gender equal attitudes, beliefs about gender roles, and gender equal behavior in the home. It also found whether participants achieving healthy gender behaviors in the family differed from their parental examples, confirming a departure from socialization that could be due to spiritual formation. Initial interpretations between spirituality and gender beliefs and behaviors revealed no revelatory correlations (in a majority) of participants, and respondents did not, in general, differ from their parental examples.

However, the context, history, and present-day battle for gender equality and sustainability in India reveal the need for focus in this field, and results of this study displayed a relationship between spirituality and gender equality that is intriguing and invites further attention. Previous work shows that a bridge between spirituality, gender equality, and sustainable development is logical despite its absence thus far in related discourses. Indian spiritual philosophies in particular lead to the selfpurification, consciousness, and connection on which gender equality and social change thoroughly rely. This work illuminates a potential in India for gender equality discourse, encompassed by spiritual practice and philosophies, to positively affect one's deeper beliefs about gender equality and gender roles and ability to integrate gender equal behaviors into daily life.

Though India is a land conflicted with inequalities and exploitations, they are contradictions to the purest essence of its culture and profound spiritual inspirations--which intrinsically value the true self and disregard gender. Today, women and men alike continue to fight for the right and equal place of India's daughters. As the battle wages, India's unparalleled and dynamic exploration into spirituality is well-situated to achieve a more gender equal and just society--and a way forward for the ethical and sustainable development on which all will rely.

Acknowledgements: This study would like to thank DSVV and Prof. Chinmay Pandya for their support and facilitation. This is a condensed version of the original report, written as a part of the semester abroad curriculum on India: Sustainable Development and Social Change with World Learning/School for International Training (SIT), Jaipur.

ERIN SMITH, B.A. Student, Department of International Studies, University of Nebraska, Omaha, U.S.

\section{REFERENCES}

Acharya, S. S. (2014). Who Am I? Haridwar: Brahmavarchas.

Alsop, R, Fitzsimons, A, \& Lennon, K. (2002). Theorizing Gender. Cambridge: Polity.

Berkel, L .A., Vandiver, B. J. \& Bahner, A. D. (2004). Gender Role Attitudes, Religion, and Spirituality as Predictors of Domestic Violence Attitudes in White College Students. Journal of College Student Development, 45(2), 119-133.

Bryant, A. N. (2007). Gender Differences in Spiritual Development During the College Years. Sex Roles, 56(11), 835-846. 
Chakravarti, U. (1993, April 9). Conceptualizing Brahmanical Patriarchy in Early India: Gender, Caste, Class and State. Economic and Political Weekly, 28, 579-583.

Derné, S. (1994). Hindu Men Talking About Controlling Women: Cultural Ideas as a Tool of the Powerful. Sociological Perspectives, $37(2), 203-27$

Fukuyama, M. A. \& Sevig, T. D. (1999). Integrating spirituality into multicultural counseling. Thousand Oaks: Sage.

Hooks, B. (2000). Feminism is for Everybody. Cambridge: South End Press.

Joshi, K. (1999). The Veda and Indian Culture. Delhi (DL): Motilal Banarsidass Publishers.

Kabir, M. \& Kumar, T. (2004). Measuring Women's Empowerment: Indicators and Measurement. Social Change, 34(3), 64-77.

Kaufman, M. (1999). Men and Power. Halifax: Fernwood.

Knapp, S. (2006). Vedic Culture/Hinduism: A Short Introduction. Retrieved from http://stephenknapp.com

Kothari, A. (2014). India 2100: Towards Radical Ecological Democracy. Futures, 56, 62-72.

Mugali, S. (2014). A Perspective Study of Human Rights in India. International Journal of Research- Granthaalayah, 2(1), 47-54.

Pande, R. (2007). Gender, Poverty and Globalization in India. Development, 50, 134-140.

Passalacqua, S. \& Cervantes, J. M. (2008). Understanding Gender and Culture within the context of spirituality: Implications of counselors. Counseling and Values, 52(3), 224-239.

Rowen-Campbell, D. (1999). Development with Women. New Delhi: Chaman Enterprises.

Scott, J. (1986). Gender as a useful category of historical analysis. In R. Parker \& P. Aggleton (Eds.), Culture, Society, and Sexuality: A Reader. New York: Routledge.

Sharpe, J. (2003). Doing Gender and Development: Understanding Empowerment and Local Gender Relations. Oxford: Blackwell Publishing.
Shiva, V. \& Bedi, G. (2002). Sustainable Agriculture and Food Security: the Impact of Globalization. Thousand Oaks: Sage Publications.

UN Women. (2014). UN Entity for Gender Equality and the Empowerment of Women. URL accessed 15 Oct 2014. http://www.un.org/womenwatch/osagi/pdf/factsheet2.pdf.

UNDP in India. (2014). Gender Equality a Pressing Development Challenge, says UNDP Head in India. URL accessed 29 Nov 2014. http://www.in.undp.org.

VanKlinken, A. (2013). Transforming Masculinities in African Christianity: Gender Controversies in Times of AIDS. Farnham and Burlington: Ashgate.

Ver Beek, A. K. (2002). Spirituality: A Development Taboo. Development in Practice, 10(1), 31.

${ }^{1}$ See: UN 2013 Human Development Report (2014). Available at: http://www.undp.org ;

UN Progress of World's Women: Access to Justice (2014). Available at: http://progress.unwomen.org/gender-justice-and-themillennium-development-goals;

Ministry of Statistics and Programme Implementation (2012). Available at: http://mospi.nic.in/Mospi_New/site/inner.aspx?status $=3$ \&menuid $=31$

India National Family Health Survey (2005-06). Available at: http://dhsprogram.com/pubs/pdf/SR128/SR128.pdf

Legal India (2014). "Rape Laws in India". Available at: http://www.legalindia.in/rape-laws-in-india

${ }^{2}$ See Chakravarti, U. (1993). Conceptualizing Brahmanical patriarchy in early India: Gender, caste, class and state. Economic and Political Weekly, 33(1), 17-19.

${ }^{3}$ See Bhatt, A. (2008). "The Sita Syndrome: Examining the Communicative Aspects of Domestic Violence from a South Asian Perspective". Journal of International Women's Studies, 9(3), 155173.

Ahmad, N. (2009). Sati Tradition- Widow Burning in India: A Sociolegal Examination. Web Journal of Current Legal Issue, 29(2). http://webjcli.ncl.ac.uk/2009/issue2/ahmad2.html 
Nawal, N. (2009). "Child Marriage: A Silent Health and Human Rights Issue". Reviews in Obstetrics \& Gynecology, 2(1), 51-56.

Sabarwal, S; Santhya, K.G. \& Jejeebhoy, S. (2013). Women's Autonomy and Experience of Physical Violence Within Marriage in

Rural India. Journal of Interpersonal Violence, 29(2). doi: $10.1177 / 0886260513505144$

${ }^{4}$ See: Rocca, C. H., Rathod, S. Falle, T. Pande, R. P. \& Krishnan, S. (2009). Challenging assumptions about women's empowerment. International Journal of Epidemiology, 38(2), 577-585.

Unterhalter, E. \& Dutt, S. (2001). Gender, Education and Women's Power: Indian state and civil society intersections in DPEP (District Primary Education Programme) and Mahila Samakhya. Compare, 31(1), 57-73.
Nussbaum, M. C. (2001). India: Implementing Sex Equality through Law. Chicago Journal of International Law, 2(1). Available at: http://chicagounbound.uchicago.edu/cjil/vol2/iss $1 / 4$

5-See Pargament, K. I. (1997). The psychology of religion and coping: Theory, research, and practice. New York: Guilford Press.

Lukoff, D., Lu, F.G. \& Turner, R. (1995). Cultural considerations in the assessment and treatment of religious and spiritual problems. Journal of Nervous and Mental Disease, 180(11), 673-682.

Miller, M. (1995). Culture, spirituality, and women's health. Journal of Obstetric, Gynecologic, and Neonatal Nursing, 24(3), 257-263. 